\title{
Evaluación de Imputabilidad Penal en Crímenes Sexuales.
}

\section{Assessment of Criminal Imputability in Sexual Crimes.}

Leticia R. de Almeida ${ }^{1}$, Alexandre Martins-Valença²

This article aims to define sexual crime, to study the relationship between sexual crimes and mental disorders. Aspects of psychiatric expertise of individuals Who have committed sex crimes are also described. The assessment of criminal imputability is extremely important in order to adjust, in each case, the application of security measures and appropriate criminal and correctional sanctions.

Keywords: sexual crime; rape; psychiatric expertise; penal responsibility Rev Chil Neuro-Psiquiat 2020; 58 (4): 447-450

$\mathrm{S}_{\mathrm{i}}^{\mathrm{c}}$ e considera al crimen sexual como un ipo de comportamiento violento. Este último puede definirse como el uso intencional de la fuerza o de la acción física contra una persona, ya sea como coerción o como un fin en sí mismo, causando le así un daño físico o moral a la víctima, lo cual necesariamente caracteriza este comportamiento como criminal. A su vez, los delitos sexuales son todos aquellos actos delictivos que tienen como propósito la satisfacción sexual (enfoque motivacional), o aquellos cuya naturaleza es una relación sexual en cualquiera de sus formas (enfoque legal). ${ }^{1}$

La violencia sexual es un concepto multidimensional, que tiene varias definiciones, dependiendo del grupo profesional o del contexto en el que se utiliza. Para Bradford et al. $^{2}$, la violencia sexual puede definirse como cualquier comportamiento sexual contra una persona que no ha dado su consentimiento, incluyendo también la violencia física asociada con una parafilia. En general, incluye la violencia física extrema, asociada con la actividad sexual impuesta a la víctima. Debido a que los actos de violencia son contra parejas que no los han autorizado, los autores de estos actos se clasifican como agresores o delincuentes sexuales.

La violencia sexual es un fenómeno mundial que tiene efectos duraderos en la salud física y mental de las personas. También hay

Los autores declaran no tener conflictos de intereses

Aceptado: 2020/08/06

Recibido: 2020/03/04

1 Psiquiatra Forense - Instituto de Psiquiatria-Universidad Federal de Rio de Janeiro - IPUBUFRJ.

2 Máster y Doctor en Psiquiatría-Instituto de Psiquiatria-Universidad Federal de Rio de Janeiro IPUB-UFRJ. Profesor Asociado del Departamento de Psiquiatría y Salud Mental - Universidad Federal Fluminense - Niterói-RJ 
complicaciones para la vida sexual y reproductiva de las víctimas, que siguen a corto y largo plazo, tales como la infección por el virus del SIDA ${ }^{3}$. Esta forma de violencia está dirigida a hombres y mujeres de todas las edades y puede tener diversas formas de presentación. No se limita sólo a actos de relaciones sexuales no consentidas (violación o intento de violación), pero puede implicar la penetración de otras partes del cuerpo, utilizando el pene, los dedos u otros objetos. Otros delitos sexuales incluyen caricias o actos de afecto inapropiados, besos, acoso, coerción, etc.

Es bien sabido que el número de denuncias relacionadas con estos crímenes es mucho menor que la realidad. Esto se debe al pacto de silencio compartido por la víctima, la familia y la sociedad. La víctima, avergonzada, teme el impacto de su revelación, y de que no crean en ella, o de ser acusada o expulsada de su medio. La prevalencia, la magnitud y las secuencias de esta situación han merecido cada vez más la atención de los estudiosos e investigadores de la salud y los derechos humanos.

El criterio biopsicológico, aplicado en países como el Brasil, exige la investigación de la existencia efectiva de una relación de causalidad entre el estado mental anómalo y el delito cometido, es decir, que este estado, contemporáneo a la conducta, haya privado parcial o completamente al agente de cualquiera de las capacidades psicológicas antes mencionadas (sea el intelecto o la volición). No basta diagnosticar sólo el trastorno mental, también debe ser investigado si la presencia del mismo ha afectado la comprensión y la determinación de la persona, y en qué forma lo ha sido. En la evaluación durante el peritaje, el experto debe investigar tanto los factores criminogénicos (que motivaron el crimen), como los factores criminodinámicos (como ocurrió el delito, cuál es la dinámica del mismo). Siempre que haya dudas sobre la salud mental del acusado, es indispensable la realización del examen psiquiátrico forense

En la evaluación pericial relacionada con los delitos sexuales, es muy importante que el perito consulte toda la información contenida en el expediente del proceso penal: circunstancias y lugar del delito, tipo de delito sexual, víctimas afectadas, edades de las mismas, testimonio de testigos y del propio sujeto periciado durante su testimonio ante las autoridades policiales, etc. En la entrevista psiquiátrica le corresponde al perito evaluar la versión del sujeto periciado para el crimen que se le imputa, además de aclarar el comportamiento del sujeto periciado antes, durante y después del delito. A continuación, el perito realizará la colecta de informaciones que darán sustrato a la anamnesis: antecedentes de la enfermedad actual (en caso de que haya este informe), antecedentes personales, familiares y psicosociales. Posteriormente, el perito deberá describir el examen psíquico, señalar si existe o no trastorno mental y evaluar el estado mental para la época de los hechos (evaluación de la comprensión y la determinación). Por último, deberá responder a las preguntas de las distintas partes: juicio, fiscalías, defensoría, abogado defensor, etc.

Los delincuentes sexuales sin diagnóstico psiquiátrico, una vez que se verifica la plena presencia de la comprensión y la determinación, son imputables. Las parafilias son trastornos de preferencia sexual que no provocan la obnubilación de la conciencia, trastornos sensoperceptivos o juicio de la realidad. Por lo tanto, la gran mayoría de los parafílicos sin comorbilidades psiquiátricas son imputables. En la esquizofrenia y otros trastornos psicóticos, los delitos sexuales pueden estar motivados por delirios y alucinaciones, siendo más comunes en estos casos la inimputabilidad, con la declaración de medidas de seguridad (sentencia judicial). En los delitos sexuales cometidos por pacientes com síntomas maníacos, la inimputabilidad es más co- 
mún, siempre que el trastorno del estado de ánimo afecte la comprensión y la determinación en relación con el delito. Los cuadros demenciales con grave deterioro cognitivo en general también caen en la inimputabilidad.Con respecto al retraso mental, la imputabilidad penal dependerá del grado de retraso mental. Los grados leves y moderados pueden presentarse con imputabilidad plena o imputabilidad parcial. Los grados graves de retraso mental se acaban más a menudo en la inimputabilidad.

Connor et al. ${ }^{4}$ describier on la prevalencia de la agresión física y sexual en la población adulta de Nueva Zelandia durante un período de 12 meses. Este fue un estudio poblacional de 16.480 adultos, donde se realizaron entrevistas computadorizadas por teléfono. Se encontró que el 1\% de las mujeres y el 0,4\% de los hombres habían relatado haber sufrido alguna agresión sexual, y que el 45\% había relatado más de una agresión sexual. Las víctimas de agresión sexual describieron el uso de alcohol por parte de los perpetradores en el $57 \%$ de los incidentes. Los perpetradores que estaban consumiendo alcohol en el momento de la agresión sexual eran más desconocidos para las víctimas, y las agresiones ocurrieron con poca frecuencia en las casas de las víctimas, en comparación con las agresiones en las que los perpetradores no estaban usando alcohol.

Además del impacto de estas agresiones sexuales y el sufrimiento causado a las víctimas y familiares, las agresiones sexuales relacionadas con el consumo de alcohol y drogas tienen importantes implicaciones para las autoridades policiales, judiciales y de atención a la salud. Langevin y Lang ${ }^{5}$ señalan la importancia de incluir el abuso de sustancias en la evaluación y el tratamiento de los agresores sexuales, señalando que los hallazgos de la literatura han encontrado más alcohólicos entre los agresores sexuales que en la población general. El abuso de alcohol y sustancias es una preocupación importante para los profesionales que trabajan con agresores sexuales. Estos profesionales deben recibir capacitación en el área del abuso de alcohol y drogas.

La evaluación psiquiátrica-forense de la responsabilidad penal en delitos sexuales se lleva a cabo sobre la base del análisis de la capacidad de la comprensión y la determinación del sujeto objeto del peritaje. A su vez, la evaluación de estos aspectos implica un estudio cuidadoso del expediente del proceso penal, antecedentes personales, familiares y psicosociales de los sujetos peritados, además del examen psicopatológico. Este último implica el conocimiento de la psicopatología y la investigación exhaustiva de todas las funciones psíquicas del individuo durante la entrevista psiquiátrica, como la conciencia, el juicio de la realidad, la percepción sensorial, la inteligencia, la afectividad y la voluntad. Sin duda, el examen psicopatológico es una parte fundamental en la evaluación de la responsabilidad penal en estos casos.

La investigación sobre la etiología de los delitos sexuales y la evaluación de los agresores sexuales es la única manera de reducir las consecuencias y los costos de estos problemas para la sociedad, así como el inmenso sufrimiento ocasionado a las víctimas. Los programas de tratamiento de problemas relacionados con el alcohol y las drogas pueden contribuir a la reducción de la recurrencia criminal de los agresores sexuales, además de involucrarlos en un entorno terapéutico.

\section{Resumen}

El artículo tiene como objetivo definir el crimen sexual y estudiar la relación entre los crímenes sexuales y los trastornos mentales. También se describen aspectos del 
peritaje psiquiátrico de las personas que han cometido delitos sexuales. La evaluación de la imputabilidad penal es extremadamente importante para ajustar, en cada caso, la aplicación de medidas de seguridad y las sanciones penales y correccionales apropiadas.

Palabras clave: crímen sexual; violación; peritaje psiquiátrico; imputabilidad penal

\section{Referencias Bibliográficas}

1.- Duque C. Parafilias e Crimes Sexuais. In: Taborda JGV, Chalub M, Abdala-Filho, E, eds. Psiquiatria Forense. Porto Alegre: Artmed, 2004; p. 297314.

2.- Bradford, JM. Sexual deviancy. Current Opinion in Psychiatry 1994; 7 : 446-451.

3.- $\quad$ Krug EG, Dahlberg LL, Mercy J, Zwi $\mathrm{AB}$, Lozano R. eds. World report on violence and health. Geneva, World Health Organization 2002; p.147-179.
4.- Connor J, You R, Casswell S. Alcohol-related harm to others: a survey of physical and sexual assault in New Zealand. N Z Med J 2009; 122 (1303): 10-16.

5.- Langevin R, Lang RA. Substance abuse among sex offenders. Ann Sex Res1990; 3:397-424.
Correspondencia:

Leticia Rodrigues de Almeida, Avenida Prado Júnior, 135/1005, Copacabana, Rio de Janeiro/RJ. Teléfono: (21) 985523453 